\title{
Redox control on the seawater tungsten isotope composition
}

\author{
FLORIAN KURZWEIL ${ }^{1}$, COREY ARCHER ${ }^{2}$, MARTIN \\ WILLE $^{3}$, RONNY SCHOENBERG ${ }^{4}$, CARSTEN MÜNKER $^{5}$ \\ AND OLAF DELLWIG ${ }^{6}$
}

${ }^{1}$ University of Cologne

${ }^{2}$ ETH Zürich

${ }^{3}$ University of Bern

${ }^{4}$ University of Tuebingen

${ }^{5}$ Universität zu Köln

${ }^{6}$ Leibniz Institute for Baltic Sea Research

Presenting Author: fkurzwei@uni-koeln.de

Manganese oxides are a major sink for dissolved marine $\mathrm{WO}_{4}{ }^{2-}$ and $\mathrm{MoO}_{4}{ }^{2-}$. During adsorption of $\mathrm{WO}_{4}{ }^{2-}$ and $\mathrm{MoO}_{4}{ }^{2-}$ onto $\mathrm{Mn}$ oxides the coordination of $\mathrm{W}$ and Mo changes from tetrahedral to octahedral [1]. Light isotopes are preferentially adsorbed due to the weaker bonding structure in octahedral coordination. Sulfidic settings are another major sink for Mo, but not for $\mathrm{W}[2,3]$. In contrast to Mo, the $\delta^{186 / 184} \mathrm{~W}$ of seawater and authigenic sediments is therefore expected to be independent of the global extension of sulfidic conditions but more intimately linked to the extension of oxic marine conditions.

We present seawater $\delta^{186 / 184} \mathrm{~W}$ and $\mathrm{W}$ concentration data from the South Atlantic Ocean and the South China Sea showing an average $\delta^{186 / 184} \mathrm{~W}$ of $+0.543 \pm 0.046 \%$ o $(2 \mathrm{SD} ; \mathrm{n}=10)$ at an average $\mathrm{W}$ concentration of $0.050 \pm 0.007 \mathrm{nM}(2 \mathrm{SD} ; \mathrm{n}=10)$. These estimates are perfectly consistent but more precise than a previous estimate on Northern Pacific seawater [4] and clearly indicate a conservative distribution of $\mathrm{W}$ in modern open ocean seawater. In contrast, seawater from a redox-stratified basin in the more restricted Baltic Sea (Landsort Deep) shows more variable $\mathrm{W}$ isotope compositions $\left(\delta^{186 / 184} \mathrm{~W}\right.$ between +0.347 and $+0.810 \%$ ) and $\mathrm{W}$ concentrations (between 0.054 and $0.223 \mathrm{nM}$ ). Consistent with experimental studies [1], the preferential scavenging of isotopically light $\mathrm{W}$ by $\mathrm{Mn}$ oxides that form along the redoxcline in this basin increases the $\delta^{186 / 184} \mathrm{~W}$ of surrounding seawater, whereas the re-dissolution of $\mathrm{Mn}$ oxides causes decreasing seawater $\delta^{186 / 184} \mathrm{~W}$. Our findings suggest that redoxrelated processes cause variations in the abundance and stable isotope composition of marine $\mathrm{W}$ thus providing the initial framework for the future application of stable $\mathrm{W}$ isotopes as a new paleo-redox proxy.

[1] Kashiwabara et al. (2017) GCA 106, 364-378.

[2] Mohajerin et al. (2016) GCA 177, 105-119.

[3] Dellwig et al. (2019) ESR 193, 1-23.

[4] Fujiwara et al. (2020) Chemical Geology 555, 119835. 